\title{
Progress in Japanese Population Geography: Retrospect and Prospect
}

\author{
ISHIKAWA Yoshitaka \\ Department of Geography, Kyoto University, Sakyo-ku, Kyoto 606-8501, Japan
}

\begin{abstract}
This paper reviews the existing literature on Japanese population geography since 2000 by major population topics, including projection, birth/death, migration, distribution, and household/marriage. Among these themes, migration studies (in particular, internal migration) still occupy a considerable proportion. The increase of GIS-based investigations is worthy of attention. Concerning the contribution of Japanese population geography as a whole, the following two things can be demonstrated. First, some Japanese population geographers have published major works in prestigious English foreign journals and have eagerly pursued international comparisons or joint studies with foreign researchers. Second, much of the research presumably deals with the manifold empirical aspects of the geographical impacts of Japan's population decline. Finally, a few problems concerning the existing literature are also mentioned.
\end{abstract}

Key words: population geography, population decline, migration, residential mobility, population projection

\section{Introduction}

Japan's population, which peaked at 127,817,000 in December 2004 and started to decrease in January 2005, is estimated to show a nearly $30 \%$ decline over the next fifty years. Such a population trend has attracted great attention in Japan's academic, administrative, and business circles. Such population decline is not necessarily observed in many developed countries, although similar movement can be found in Southern/Central/Eastern European countries (Ishikawa 2007: 6-8). In particular, such Englishspeaking countries as the US and the UK, which are currently the world's leaders in geographical research, are still experiencing population growth due to immigration. As a result, scant attention is being paid to the possible geographical impacts of population decline. For such investigations, Japan occupies a potentially promising position.

This paper reviews the existing literature including books and refereed papers on Japanese population geography published from 2000 to 2006. Several studies published in 2007 are also included. A special issue of the Geographical
Review of Japan, including this paper, is published for the 2008 Tunis International Geographical Congress (IGC). Therefore, after introducing the contents of important studies, I would like to discuss the specific significance of the existing literature.

This review is restricted to works published since 2000 for two reasons. First, two review papers that concentrated on Japanese population geography or regional demography were published in the late 1990s (Ishikawa 1997; Otomo 1998). In addition, since the number of studies of Japanese population geography published after 2000 is approximately one hundred, such a rich vein of literature deserves detailed examination. Second, as mentioned above, in Japan, concerns about population decline based on long-range population projections by the $\mathrm{Na}$ tional Institute of Social Security and Population Problems have been attracting great attention. In particular, the projection conducted in 2002 was influential. A salient feature of recent research in population geography is that a certain portion is written explicitly or implicitly with this trend in mind. Unfortunately, however, no review has scrutinized population decline, even though such a work could provide a new perspective for the 
whole context of population geography in the world. Such interest has rarely been stated in previous review papers (Ishikawa 1997; Otomo 1998).

Throughout this paper, the term "Japanese population geography" implies the following three meanings: first, studies of Japanese population; second, population studies by Japanese geographers; and third, studies of foreign populations published in geography journals in Japan. Among them, most studies fall under both the first and second categories, because basically no studies of the Japanese population by foreign geographers are considered here. About ten studies are only grouped into the second category and specifically correspond to research of foreign populations by Japanese geographers. A few papers are only applicable to the third category; most are population investigations reflecting the countries of respective authors.

Although population geography covers many subjects, recent publications by major population themes including projection, birth/death, migration (internal, intra-urban, and international), distribution, and household/marriage are sequentially discussed for reader convenience. These themes not only reflect the main studies of traditional population geography but also the growing concern for new topics.

Before proceeding, note that since two books by Otomo (2003, 2006), which gave brief but fruitful descriptions of various topics concerning national populations in the world, cannot be grouped into one of these themes, they are cited here. Topics of the elderly and ethnic groups are also crucial constituents of population geography; unfortunately, however, they are beyond the scope of this paper due to space limitations and the existence of good review papers (Tahara et al. 2003; Chiba 2005).

\section{Population Projection}

The continued decline of Japan's population has created great interest in population declinerelated issues. For example, many books with the term 'population decline' in their main- or subtitles have been recently published (Ishikawa 2007). These publications are generally based on the long-range population projections of the $\mathrm{Na}$ - tional Institute of Social Security and Population Problems. This projection is now given not only for Japan as a whole but also for each prefecture and local municipality (shi/ku/machi/mura). Noteworthy is that a few members of the institute are geographers (M. Shimizu, S. Koike, and M. Yamauchi) who played important roles in these projections. Interestingly, projection by local municipality was conducted first in 2003 mainly by them. As a result, the net migration rate of a particular local municipality in the future is assumed by incorporating the recent rates of neighboring municipalities (Koike et al. 2004). This means a consideration of spatial effect, and thus, is expected to improve projection accuracy by mitigating the serious problem of small and unstable numbers in net migration term by municipality.

In his excellent reaction to the coming age of population decline in Japan, Esaki (2006) scrutinizes various aspects of the future population in the Tokyo metropolitan area. Even though it is the largest metropolitan area and has enjoyed a "mono-polar concentration into Tokyo" in terms of population and higher urban functions, he is not optimistic about its population geographies due to several issues including wide-ranging depopulation in its suburbs.

Additionally, another example is a publication edited by Ishikawa (2007) that includes 11 papers divided into the following three parts: 'birth, family, retirement, and death,' 'migration of the Japanese population,' and 'migration of foreign population.' The contributors examine the manifold aspects of population decline from geographical perspectives and present policy implications based on their findings. Although the book's content is somewhat biased to migration research, it can be justified because migration is generally more difficult to predict than birth and death, particularly on smaller spatial units (Koike et al. 2004). This book is a systematic attempt to examine issues associated with population decline from the viewpoint of human mobility.

\section{Birth and Death}

Next, literature concerned with birth and death, two constituents among the three demo- 
graphic events, is discussed. A major determinant of population decline in Japan is the fall of fertility below replacement level since the mid1970s. However, the geographical literature on these topics is scarce.

Yamauchi (2006) develops a new fertility measure by amending the child-woman ratio, which is a traditional measure of fertility. Nakagawa (2003) investigates long-term fertility trends in Japan at both national and prefectural levels. Regarding the past two decades, he mentions the rapid decline of the total fertility rate (TFR) in almost all prefectures that is chiefly due to the decline of married females and the symptoms of the "second demographic transition" (van de Kaa 2002); these symptoms are now spreading from well-urbanized areas to the rest of the country.

In addition, Yamauchi et al. (2005) analyzed the spatial patterns of fertility in terms of the child-woman ratio and obtained the following findings. Fertility decline since 1980 was observed regardless of the size of the metropolitan area. The fertility rate of Tokyo is the lowest and is rapidly declining. Furthermore, in this area fertility exhibits a concentric zonal pattern characterized by lower values in the central part and higher ones in the outer part.

The fall of TFR can be decomposed into the fall of the marital rate and marital fertility; the former has been more influential than the latter (Nakagawa 2003). Since more attention has been paid to TFR than the marital rate in the existing literature, the regional imbalance of the marital rate itself deserves more attention.

In addition, Koike (2006) examines whether the statement "migration from rural to urban areas reduces fertility" holds true for Japan using data from the Fifth National Survey on Migration conducted by the National Institute of Social Security and Population Problems. The fertility of rural-to-urban migrants was lower than rural stayers and even urban stayers. He concludes that the adaptation hypothesis seems more influential, perhaps because it assumes that migrant fertility is adjusted by adapting it to various environments at destinations.

Important research on death is also available. Referring to various interesting cases found in Japan and Europe, Kagami (2004) shows what can be learned from regional differences of disease from a geographical perspective. This excellent work suggests how geographers should treat disease. Meanwhile, papers by Nakaya (2000), Nakaya and Dorling (2005), and Nakaya et al. (2005a, b), all of which were published in English journals, are mainly characterized by theoretical/quantitative approaches for mapping or modeling disease or mortality and relationships with socioeconomic characteristics. They suggest that medical geographical study in Japan shows a higher level among various sub-disciplines of Japanese geography. Additionally, Nakaya et al. (2004) demonstrates the research frontier of this topic and explains the contribution of the Geographical Information System (GIS) as an analytical tool.

Medical geography and population geography have been regarded as rather different so far; however, remembering that for most people death does not necessarily come suddenly but comes after stages including illness or special care, these two sub-disciplines should be cooperative. In the age of population decline, when mortality is stabilized at a higher level, disease/death-related topics must receive adequate notice in population geography.

\section{Migration}

Migration is a constituent of the three demographic events as well as birth and death. In particular, internal migration has been an important focus of previous studies on population geography in Japan. Fielding (2003) argued that geography is absolutely central to the study of migration (and vice versa), and throughout the study period here, geographers have greatly contributed to migration research through empirical studies of migration flows and net migration patterns (often using quantitative methods). His statements are no doubt applicable to Japan as well. Because there have been many migration-related works in recent years, existing literature is divided into three subjects: internal migration, intra-urban migration, and international migration.

\section{Internal migration}

Migrations between core and periphery

During the 1950s and 1960s, considerable net-in- 
flows to the three largest metropolitan areas of Tokyo, Osaka, and Nagoya from the rest of the country occurred. Following Ishikawa (2001a), note that throughout this review paper, the terms 'core' and 'periphery' refer to the former and the latter, respectively. Hence, as a category of internal migration, migration between the core and the periphery is discussed before other topics are broached.

Migration turnaround (great decrease of net in-migration to the core) occurred in the 1970s; re-turnaround, or an upsurge of net in-migration to the core (particularly, the Tokyo metropolitan area), was observed in the 1980s. Although there were differences in terms of the net in-migration rate, these two turnarounds have also occurred in most advanced countries. In this sense, the Japanese experience of migration changes was not unique.

Based on such a background, migration from the periphery to the core has thus far drawn the attention of geographers (Nakagawa 2000). Investigating cases in Sweden and Canada as well as in Japan, Ishikawa (2001a) looks for the common determinants of migration turnarounds and cites the importance of factors associated with the supply and demand sides of the labor market in these countries; specifically, the former corresponds to the changing supply of young adults in response to the fluctuation of fertility since the end of World War II, and the latter is the transformation of the labor market toward tertiary sectors (especially financial and service industries) and white-collar-related occupational sectors. This study is significant because the Japanese migration turnaround experience can be understood in the wider context of the advanced world, and Ishikawa seeks the fundamental factors of the turnarounds beyond individual national experiences.

Concern with traditional periphery-to-core flows has remained active (Nakamura 2000; Yamaguchi and Esaki 2002; Inoue and Liaw 2004; Yamaguchi 2004). We introduce the contents of only two studies here. First, Inoue and Liaw (2004) address temporal changes in the sex ratio of out-migration from peripheral prefectures in Japan's post-WWII period and explain them from a life-course perspective based on traditional family views expressed by psychologist Hayao
Kawai and cultural anthropologist Chie Nakane. This paper helps reconfirm the usefulness of the simple but important measure of sex ratio for migration research.

Second, Yamaguchi (2004) may not strictly be an investigation of internal migration, but it is nonetheless quite interesting. He concentrated on the collective labor migration of new school leavers from Okinawa (Ryukyu) to mainland Japan. Okinawa was occupied until 1972 by the United States Civil Administration of the Ryukyu Islands (USCAR). The author vividly describes a complicated mixture of attitudes toward such migration among three different actors (the USCAR, the Japanese Government, and the Government of the Ryukyu Islands), the migrants' longing for the mainland, and their concerns about their destinations. This excellent paper successfully illustrates the full meaning of this special migration.

In the age of population decline, which started in 2005, the populations of all prefectures are estimated to decrease until the middle of the $21 \mathrm{st}$ century at rates on the whole larger in municipalities located in peripheral Japan. In this context, human migration from the core (specifically, the three largest metropolitan areas) to the periphery has recently attracted wide attention. Note that the massive retirement of the baby boomers has just started, and whether a significant portion of them will leave for peripheral places after retirement remains to be seen.

The terms 'U-turn' and 'J-turn' have also been notable since the migration turnaround of the 1970s (Ishikawa 2001a). The former implies the return migration of populations who left the peripheral parts for the three metropolitan areas and returned to their hometowns, and the latter implies migration that resembles 'U-turn' but differs because the destination is medium-sized cities near their hometowns mainly due to the shortage of employment opportunities. Currently, another term 'I-turn' is also popular; it is not a kind of return migration, but rather implies direct migration chiefly from the core to peripheral places that are not the hometowns of migrants. 'U-turn' and 'J-turn' are remarkable for younger populations or retirees and 'I-turn' for the middle-aged or retirees. At any rate, all three of these flows toward the country's peripheral 
portion are expected to increase (or not lose heavily) population in destination municipalities.

Recently published reports on this topic (Esaki et al. 2000; Yamaguchi et al. 2000; Tahara et al. 2000; Tanigawa 2004; Takeshita 2006; Esaki 2007) are based on questionnaires or in-depth interview surveys. Note that international retirement migration from Japan, a kind of 'I-turn', is also observed in Kubo and Ishikawa (2004).

The major findings are as follows. For 'U-turn' and 'J-turn' migration, the return rate tends to be higher for younger cohorts. Most return several years after migration from their hometowns located in the periphery to the core, often to care for elderly parents. Returning migrants often have to bear income reduction and dissatisfaction with their jobs at their destination, and so on. For 'I-turn,' municipalities in such prefectures as Okinawa and Kagoshima with mild climates are preferred. Other problems include the difficulty of becoming firmly rooted in the destination community, husbands may be more eager than wives, and so on.

A certain part of 'U-turn,' 'J-turn,' and 'I-turn' corresponds to retirement migration. Until the 1990s, almost no reports of Japanese migration motivated by retirement existed. Such a lack has aroused researcher curiosity (Ishikawa 2001a: 280-281); unlike European or North American countries, why is retirement migration not observed in Japan? Therefore, recent publications about retirement migration may reflect a new movement closely linked to the arrival of a society in population decline. Additionally, Yamaguchi et al. (2000) refer to increasing retention rates at local municipalities in peripheral prefectures, and Nakazawa (2002) demonstrates that the information service sector in Kyushu provides jobs for returning migrants.

Precisely grasping the return migration is difficult. Shimizu (2006) examines the theoretical and empirical validity of using the cumulative net migration rate to analyze the metropolitan experience and subsequent return migration among non-metropolitan natives. Using this rate is popular in existing literature concerning migration between the core and the periphery. However, he pointed out that such a popular way cannot satisfactorily analyze the actual migration behavior of natives. This paper thus contributes to improving the understanding of the prominent migration flows from the periphery and subsequent return migration.

Since human flows toward peripheral municipalities as 'U-turn,' 'J-turn,' and 'I-turn' do contribute to avoiding reinforcement of the current "mono-polar concentration into Tokyo" and lead to balanced development of the national land, I welcome the recent addition of these migration categories toward peripheral Japan.

Other internal migrations Excluding migration between the core and the periphery, next I would like to discuss other existing literature that includes increasing interest in international comparisons that are partly based on quantitative methods, internal migration outside Japan, and the migration of skilled workers.

First, attempts to undertake international comparative studies deserve attention. Yano et al. (2000) comprehensively analyzed internal migration in Japan during the boom period of 19851990 on an inter-municipal basis. Migration data on such a spatial scale previously had been unavailable, but it could be obtained from the 1990 census. This paper identifies the relative importance of destination attractiveness factors (distance from origin, population size, and access to other destinations) by applying an origin-specific competing destinations model. As a result, we learned that the maps showing the parameter estimates obtained from the model are marked by remarkable differences in the strength of factors of migration behavior. Applying a similar perspective to internal migration in the UK, Yano et al. (2003) measured and commented on the differences in the behavior of migrants in Japan and Britain. In both countries the focus is on interregional migration. The results obtained from the application of the same model employed in Yano et al. (2000) reveal interesting differences in the factors underlying destination attractiveness of the two countries; these implications are important both for the way in which migration is modeled and for its impact on the urban systems in both countries.

Another example of an international comparative study of internal migration between Japan and the UK is Fielding and Ishikawa (2003). Based on a matrix of the correlation coefficients between the age-specific net migration rate and 
age structure location quotients by prefecture, they also found some interesting differences; for example, Japan seems to be a less geographically mobile society than Britain because its local age structure reflects the age structures of net migration less than in Britain.

A remarkable contribution to migration modeling is Fotheringham et al. (2001), who extended understanding of the role of the competing destinations model and captured the effects of hierarchical destination choices by proposing a simulation experiment. They made explicit the links between spatial choice behavior at different levels of a spatial hierarchy and the way in which decisions made at one level of the hierarchy can lead to biased measurements of behavior at a lower one. This is shown when conventional spatial interaction models are calibrated with interaction data that result from hierarchical destination choices.

Inoue (2000) presented stochastic modeling of the relationship between duration of stay at a current address and previous migration rate, reinforcing the existing analytical framework of migration schedules or profiles of age-specific migration rates. To analyze the results of the Fourth National Survey on Migration, Inoue (2001) proposed a few new measures of lifetime migration. Shimizu (2002) discusses two different definitions of migration and the resultant discrepancy using the results of the same data source. Moreover, Portnov et al. (2001) developed a new model with a combined representation of employment and housing variables and demonstrated its excellent performance for Japan's internal migration.

Second, concerning research outside of Japan, there is increasing interest on internal migration in foreign countries in the recent literature. For example, Isoda (2000a) carefully studied Britain's internal migration and demonstrated the role of population circulation by analyzing the spatial patterns of age-specific migration, explaining its recent changes in relation to business fluctuations. A similar perspective is found in another paper that focused on Greater London by the same author (Isoda 2000b). In addition, Ishikawa (2005) published a collection of twelve papers that cover multiple migration topics in the Asia/Pacific region. Internal migration abroad is explored by K.-L. Liaw (US/Canada), K. Tanaka (Adelaide, Australia), S. Takahashi (Thailand), S. Nakagawa (Bangkok), H. Ishihara (China) and M. Yamada (Canada). Furthermore, as the fourth publication from the International Geographical Union's Home of Geography, Ishikawa and Montanari (2003) published a collection of contributions on internal migration in several foreign countries, providing wide diversity about human mobility in the world. Liu et al. (2005) analyzed the spatio-temporal properties of the floating population in China from 1990 to 2000 .

Moreover, I would like to note Soda's (2007) English book based on intensive fieldwork concerning the Iban in Sarawak. He convincingly explains out-migration from the villages, the living strategy of the inhabitants, their frequent movement between rural and urban locations, and kinship relations between those still living in rural communities and those now living in cities. Discussion from both rural and urban perspectives indicates that understanding Iban movement as migration practices is insufficient. He demonstrates the importance of recognizing such movement as an expansion of their living space, and thus it needs to be understood as ruralurban interaction of human mobility. This valuable contribution to population geography suggests a wide diversity of human mobility.

Third, among existing literature on internal migration, an interesting recent tendency is the attention on skilled migrants, whose migration has been an important topic in migration research, despite few studies. Convincing reports have been published on the skilled workers of the pharmaceutical industry in Tsukuba City, Ibaraki Prefecture (Sato 2004) and the information service industry in provincial regions including Hokkaido and Tohoku (Nakazawa and Arai 2003, 2004a,b). Additionally, Nakazawa (2001a,b) clarifies the concentration mechanism of recent engineering graduates into the Tokyo metropolitan area. Morikawa (2006) eschews analysis to investigate the flows by occupation among major cities caused by data unavailability. However, these flows are expected to contain a certain portion of skilled workers, and investigation of interurban migration from this perspective seems fruitful. 
Previous studies on skilled migrants are undoubtedly limited at this stage; however, minute research focusing on various categories of the skilled as valuable human capital are essential for fully understanding the significance of their mobility in the age of population decline.

\section{Intra-urban migration}

Intra-urban migration, another category of internal migration, has also attracted much attention in existing literature partly in response to an increase of Japan's urban population. There are three important focuses in this migration category: longitudinal analysis of migration, changing residential mobility, and population revival in the central parts of major cities.

Longitudinal analysis First, longitudinal studies of migration need to be mentioned, especially of urban inhabitants, whose data are collected through in-depth questionnaires or interview surveys (for example, see Tanaka 2000a: 170-283; 2000b, 2002; Esaki et al. 2000; Inagaki 2003; Nakazawa and Arai 2004b; Nakazawa et al. 2006). These researches share common perspectives about the insufficiency of cross-sectional analysis that is mainly based on census migration data.

Particularly, Tanaka's investigations of the migration careers of residents of Santa Barbara and Lexington (US), Cologne (Germany), Pretoria (South Africa), and Adelaide (Australia) are important in this context. She collects almost all migration data since the birth of the respondents, although the number of the respondents is not many. Her purpose is somewhat different from other research based on longitudinal migration data; specifically, she devotes more attention to the typology of observed migration careers and the elucidation of relationships between urban spatial structure under consideration and intra-urban migration fields.

Her focus on migration careers in urban settings seems to be a forerunner of subsequent, similar longitudinal studies. Using longitudinal data is especially helpful for examining return migration toward peripheral parts of the country (see above) and changes in intra-urban residential migration (see below).

Changing residential mobility The second important subtopic of recent intra-urban migra- tion is the increased interest in changing residential mobility.

The following view or model had been influential in previous literature of intra-urban migration. Young, single adults from outside a particular metropolitan area find their first places of residence in inner-city areas where commutes are generally shorter. After getting married, they tend to move outward to inner city or suburbs. As children are born and raised, these households often move further outward to meet the demand of housing opportunities with more space. Such a sequence of residential choices usually terminates in the outer suburbs where detached houses are readily available.

This view implicitly assumes massive in-migration of a young adult population into a metropolitan area from outside and that all inhabitants of this area marry at "marriageable" ages. However, population inflow from non-metropolitan regions has drastically dropped since the 1970s (Ishikawa 2001a), and individuals choosing to remain single or delaying marriage have been increasing in contemporary Japan. In addition, a few unrealistic assumptions are often added to this view; after getting married women stop working and become full-time homemakers; they follow their husbands' residential choices, a marriage lasts until "death do us part," and so on. Of course, such a conventional model may be applied well in particular situations, as shown by Nakazawa and Kawaguchi (2001), who report the migration behavior of residents from Nagano Prefecture who have experienced residential mobility in the Tokyo metropolitan area.

However, it is unlikely that this model can be widely applied to Japan's current situation, especially since most recently published literature is skeptical about its empirical validity. For example, good examples include the book edited by Wakabayashi et al. (2002) and the papers included in the special issue called "Residential choices and housing problems of single working women in Tokyo" of the Geographical Review of Japan (Kamiya et al. 2006; Nakazawa 2006; Wakabayashi 2006; Yui 2006). Since such a topic has seldom been considered in previous literature on intra-urban residential mobility, their main residential areas remained unknown. But according to the above recent researches, single 
working women in their 30's living alone are concentrated in the western half of the Tokyo special wards, implying that they prefer places near railway/subway stations and convenient for shorter commuting.

Yui and Yano (2000) investigated fatherless households in Tokyo and found that they prefer to live in the northern or eastern parts of the special wards where public facilities supporting such households are concentrated. Other reports for Japanese cases (Ito 2001; Taguchi 2001; Arai et al. 2002; Tani 2002; Inagaki 2003; Sato and Arai 2003) as well as a Korean case (Jung 2002) provide great diversity for the actual circumstances of intra-urban residential choices and discrepancy from the traditional intra-urban residential mobility model. Besides, there is an interesting report of one-person households of married men who are called "partial migrants." Such individuals are transferred to new workplaces but their families stay at their current residence (Ishikawa 2001b). "Partial migrants" tend to congregate in the inner areas of central cities or inner suburbs where commutes are relatively convenient.

These persons or households, including single women, fatherless households, and "partial migrants", have seldom received appropriate attention in previous literature. It is no doubt important to continue to study the residential choices of such recently increasing households in contemporary Japan. Furthermore, the traditional model of intra-urban residential mobility must be replaced by a new model that incorporates the actual, updated circumstances observed in contemporary Japan.

Population recovery in the central parts of major cities The third focus in recent intra-urban migration literature is the population recovery in the central parts of major cities since the mid-1990s (Yabe 2003; Yamagami 2003a; Sakakibara et al. 2003; Shimizu 2004a, b; Miyazawa and Abe 2005; Otsuka 2005). This new movement reflects the population revival through massive construction of condominiums, falling land prices in the central parts of major cities, and the disposal sale of real estate by private companies that suffered after the bubble economy's collapse in the early 1990s.

The following major findings are concerned with population recovery. The cause of population revival in such parts is the increase of inmigration rather than the decrease of out-migration, and migration distance by in-migrants is generally short. Policy incentives by local municipalities that encourage residential population increases have partly contributed to such recoveries. In-migrants typically are one-person households of unmarried females or a double-income-no-kids (DINK) household in their thirties, highly educated, and holding 'white-collar' jobs.

However, since detailed reports of this topic have been generally limited to case studies of the Tokyo area, at this stage, there is room for similar investigations of other large cities. Based on detailed research of populations in Tokyo, Esaki (2006) fears that the population revival is likely to subside in several years (mainly due to increasing mortality) even within the country's largest metropolitan area. This suggests that the population recovery has been rather temporary for the two decades since the mid-1990s; therefore, this population recovery movement cannot be overestimated. We may have to view this phenomenon as an aspect of changing residential differentiation, whose possible impacts in the age of population decline will need to be investigated as well.

\section{International migration}

Reflecting the significant increase of immigration since Japan's bubble economy of the late 1980 s, a proliferation of research has addressed international migration or foreigners in recent years. Let me introduce a few examples.

Ishikawa (2005) investigated the international migration turnaround (the change from net outflow to net inflow) in Japan and concluded that it took place about 1990. A time lag of about fifteen years elapsed since TFR started to fall below replacement level in the mid-1970s. The well-known second demographic transition model advocated by van de Kaa (2002) assumes simultaneity of turnaround and fertility fall. However, Ishikawa's finding suggests that his model is not applicable to the Japanese experience; it needs to be modified by incorporating the time lag, which roughly corresponds to the period of a child's growth from birth to the end of education. 
Liaw and Ishikawa (2008) analyzed destination choice in migration behavior by new immigrants who entered Japan between 1995 and 2000 and clarified the three major factors that affected their choices: labor-market conditions, co-ethnic population attraction, and international marriage opportunities. Interestingly, they note the importance of international marriage between Japanese men and foreign women as one among various reasons for immigration to Japan and demonstrate that international marriage is a strategy for entering Japan for foreign women because the Japanese government does not permit unskilled labor from abroad.

Yamamoto (2000), who also issued a report on immigration and immigrants in Sweden, is very familiar with the same topic in Germany. He concentrated on the Swedish case because only the positive aspects of immigration and issues of immigrants in Sweden have been demonstrated, at least in Japan. Based on his findings, immigrants have problems in the labor market and experience spatial segregation and xenophobia; thus, he concludes that Sweden has not been free from such negative aspects, which have also been observed in Germany. Note also the following interesting studies by Dai (2004) on migration from China to Japan and 'Esau (2004, 2005) on migration from Tonga.

Previous migration research has usually been divided into either international or internal groups, depending on whether a particular migrant crossed a national border. Although these two categories usually constitute part of this person's inseparable social process, they have been dealt with rather independently. In this sense, contributions by R. Skeldon, M. Yamada, K. Kanasaka, and T. Hisatake included in Ishikawa (2005) are encouraging, because they specifically refer to the inseparable relationships of these two migration categories in different contexts.

In Japan, one recent discussion topic about immigrants is whether "replacement migration" by foreign population can compensate for the shortages of native Japanese in the labor force or moderate depopulation-related problems, especially in peripheral municipalities (Ishikawa 2007). This is a big issue in the age of population decline, but since we have almost no geographical literature from this point of view at this stage, we cannot satisfactorily answer this question. However, by amplifying the findings obtained by Liaw and Ishikawa (2008), the following can be mentioned. As far as the two major factors of labor-market conditions and co-ethnic population attraction for destination choice by immigrants are concerned, they will probably not help peripheral municipalities showing depopulation. Instead they will reinforce the current structure. International marriage seems to be the only plausible factor that will contribute to such municipalities; but since marriage is highly personal, we must be cautious in attempting to demonstrate its role in mitigating depopulation in peripheral Japan.

\section{Distribution and Its Changes}

The spatial pattern of population distribution is a result of the combination of three demographic events (birth, death, and migration). However, when investigation by event is difficult, examination about population distribution as a whole or its changes must be undertaken.

A notable contribution in this category is an historical demographical study by Suzuki (2004). By analyzing data obtained from surveys of households and population, he elucidated the actual urbanization circumstances of the Meiji and Taisho Eras when accurate population data was not available from population censuses. Based on the painstaking job of solving the annoying problem associated with temporal stays, he presented a possible solution and applied it to Aichi, Gifu, and Mie prefectures as case areas. His method is expected to contribute to a comprehensive elucidation of Japan's demographic transition process.

Post-war Japan witnessed a remarkable change in population distribution. However, the specific contents of that change are quite complicated. The contributions to this research topic by Yamagami (2001, 2003a,b, 2006) are notable. Using metropolitan areas rigidly defined for all Japan as of $1965,1975,1985$, and 1995 and the expansion method as an analytical framework, his research pursued a careful and minute interurban comparison of population redistribution in Japan and obtained some interesting findings. For example, the counter-urbanization observed 
in the 1970s in some Western countries never occurred in Japan; the directional bias of population density distribution in the three largest metropolitan areas has been reduced; and population recovery in the central part of major cities will conspicuously occur in Tokyo, Osaka, and Fukuoka. Since Yamagami does not fully explore the possible causes of such redistribution in socio-economic terms, it needs to be tackled in the future.

Moreover, the exploration into population distribution and its changes, which has shown considerable progress in recent years due to the supply of digital population data and the development of the GIS, deserves attention. As demonstrated in a comprehensive description concerning geodemographics by Otomo (2002), a population distribution study is very compatible with GIS-related work. Let me cite only a few examples.

The first example is an interesting attempt to estimate population distribution from topographical maps for the period before the first national census in 1920 (Koike and Arai 2001; Koike 2003). The second example is an ambitious study by Masuyama and Okabe (2003), who proposed a robust methodology to analyze intra-urban population distribution based on structural features derived from population density by district. The third example is a gender atlas edited by Takeda and Kinoshita (2007). This publication consists of four parts (marriage, work, child-raising/education, and life/welfare) and presents a series of nationwide maps on a local municipality basis or metropolitan maps on a neighborhood basis chiefly of female populations. Some of the topics included in this atlas have been discussed in existing literature, but others have seldom been examined so far, suggesting new geographical subjects. This production is considered a fruitful result based on previous studies and a point of departure for future investigations both in population geography and gender research.

\section{Households and Marriage}

The fall of TFR below replacement level since the mid-1970s is the principal cause of Japan's population decline, and this fertility trend is closely linked with increasing interest in house- holds and marriage. Regarding the specific relationship between households and marriage, currently diversifying households reflect the results of such choices as marriage (and possible divorce) or remaining single in contemporary Japan. This demonstrates that marriage plays an important role in population geographies, as suggested by Nakagawa (2000, 2001). Additionally, a few papers exhibit a great interest in gender differences in migration or life course (Tani 2002; Nakagawa 2004; Nakazawa and Kamiya 2005; Nakazawa et al. 2006).

Generally, the spatial pattern itself of household/marriage-related measures in Japan can be easily 'visualized' by GIS. As a result, we have learned the following. For example, the nuclear family predominates in the three largest metropolitan areas and western Japan and the stem family in such peripheral regions as Tohoku, Hokuriku, and San'in. The unmarried rate of female populations is high in the central parts of the major metropolitan areas, and that of male populations is notable in the country's rural/peripheral parts (see Takeda and Kinoshita 2007: 10-13, 20-23). Unmarried women of the former have attracted great attention particularly in Tokyo (Wakabayashi et al. 2002; Nakazawa 2006; Kamiya et al. 2006; Wakabayashi 2006; Yui 2006). Regarding the latter, male populations who will succeed to take over farm households have often suffered a marriage squeeze due to an imbalance of sex ratio; a certain portion of them have been urged to accept marriage with foreign women (Ochiai et al. 2007).

Besides, Yui (2007) elucidates the regional disparity of household diversification in Japan on a prefectural/municipality basis using GIS-based maps and devotes particular attention to the spatial patterns of one-person households, marital status (particularly, 'unmarried,' and 'divorced' categories), and TFR. Recent discussion associated with low fertility or policy measures to deal with it has been rather insensitive to this topic's spatial aspects, and thus careful research from a geographical perspective is essential for fully examining various issues in the age of population decline.

Multiple attitudes toward marriage and resultant household diversification have focused great attention on intra-urban residential mobility as 
well. Since the topic of household/marriage to a certain extent overlaps intra-urban migration, further discussion is avoided.

An interesting result included in the topic of household and marriage is Kobayashi et al. (2006), who carefully investigated population geography in terms of cohabitation, nuptiality, divorce, and abortion in Japan and Slovakia. Since Japan and most Southern, Central and Eastern European countries including Slovakia share similar levels of fertility and mortality, international comparisons with such countries are very useful for understanding the Japanese experience within a global context. Further comparative study must be pursued.

\section{Concluding Remarks}

This paper reviewed the recent literature of Japanese population geography published since 2000 and cited the significances and remaining problems by the following major population themes: projection, birth/death, migration, distribution, and household/marriage. Compared with the two previous reviews (Ishikawa 1997; Otomo 1998), we confirmed that migration studies (especially, internal migration) still occupy a high proportion. An increase of GIS-based investigations is worthy of attention, but this is also observed in foreign countries.

The following two things have been demonstrated about the contribution of Japanese population geography as a whole. First, even though part of the recent literature on population geography referred to here was written by urban or social geographers, Japanese population geographers have published major works in prestigious English journals and have eagerly pursued international comparisons or joint studies with foreign researchers. This merit, which especially applies to investigations of mortality and internal migration, must be sustained. Second, whereas laborious investigations of traditional subjects (for example, population distribution) continue, a portion of the recent literature has tackled newly emerging phenomena, including human migration toward peripheral parts, the changing intra-urban residential mobility associated with household diversification, and the population revival of the central parts of major cities. Even though individual studies may appear different, when seen together, this research deals with the manifold empirical aspects of the geographical impacts of Japan's population decline, and in this sense, as a whole they convincingly exhibit a research orientation toward population decline. Furthermore, very recent investigations by Esaki (2006) and Ishikawa (2007) have obviously examined the actual situation and possible issues associated with Japan's population decline. Bearing these in mind, Japanese population geographers will be able to make greater contributions to population geography in the world by devoting greater attention to the possible issues of this topic.

However, problems concerning the existing literature also need to be noted. First, partly reflecting the spatial concentration of population researchers in Japan, studies of current population geographies have tended to focus on the Tokyo metropolitan area. Researches on other areas are required. Second, recent literature has tackled specific aspects of the newly emerging phenomena associated with population decline. But, at this stage an explanatory framework that integrates such aspects is obviously insufficient; we need to construct such frameworks. Third, recent research has generally concentrated on empirical investigations; but, except, for example, Liaw and Ishikawa (2008), they have somewhat passively referred to policy implications. We population geographers must assertively explain and proclaim the policy relevance of our research findings in the age of population decline.

Finally, I would like to emphasize one more thing. Publishing major results in English enables dissemination to other countries, some of which have entered or are approaching total population decline. The population-related experiences observed in Japan can be very helpful for such countries.

\section{Acknowledgements}

The author is grateful to the Japan Society for the Promotion of Science for its financial support by grantin-aid number 18320134. The author would like to acknowledge the helpful comments of anonymous referees on an earlier version of this paper. 
(Received 31 July 2007)

(Accepted 31 October 2008)

\section{References}

Arai, Y., Kawaguchi, T., and Inoue, T. eds. 2002. Migration in Japan: Life course and regional variety. Tokyo: Kokon-shoin. (J)

Chiba, T. 2005. Ethnicity. Japanese Journal of Human Geography 57: 325-331.(J)

Dai, E. 2004. Economic development and emigration: A study on the origin structure of the new Chinese migrants. Annals of the Japan Association of Economic Geographers 50: 46-62. (JE)

Esaki, Y. 2006. The future population of Tokyo: $A$ population geography of city center and suburb. Tokyo: Senshu University Press.(J)

Esaki, Y. 2007. Return migration to rural regions in Japan: An analysis of 'The Fifth National Survey on Migration, 2001'. Journal of Population Problems 63(2): 1-13. (JE)

Esaki, Y., Arai, Y., and Kawaguchi, T. 2000. Return migration in Japan: A comparative analysis of migrants returned to Nagano and Miyazaki Prefectures. Japanese Journal of Human Geography 52: 190-203. (JE)

'Esau, R. L. 2004. International migration from Tonga, South Pacific: A behavioral approach. Geographical Review of Japan 77: 352-367.

'Esau, R. L. 2005. University education and migration experiences in the South Pacific Region: Survey of Tongans in Fiji. Geographical Review of Japan 78: 753-768.

Fielding, A. J. 2003. Geography and migration: A review and evaluation of contemporary research. Japanese Journal of Human Geography 55: 352-366.

Fielding, A. J., and Ishikawa, Y. 2003. Migration and the life course in contemporary Japan. Geographical Review of Japan 76: 246-257.

Fotheringham, A. S., Nakaya, T., Yano, K., Openshaw, S., and Ishikawa, Y. 2001.Hierarchical destination choice and spatial interaction modeling: A simulation experiment. Environment and Planning A 33: 901-920.

Inagaki, R. 2003. Migration behavior of the suburban second generation: A case study of Kozoji New Town. Geographical Review of Japan 76: 575598. (JE)

Inoue, T. 2000. Stochastic modeling of the relationship between duration of residence and previous migration rate. Journal of Population Studies 26: 29-34. (JE)

Inoue, T. 2001. Lifetime migration in Japan. Journal of Population Problems 57(1): 41-62. (JE)

Inoue, T., and Liaw, K.-L. 2004. Life-course perspective on some distinctive features of migration from non-metropolitan prefectures in Japan. Geographical Review of Japan 77: 181-198.

Ishikawa, Y. 1997. Population and migration. In Results and remaining issues: $V$, ed. The Japan Association of Economic Geographers, 247-261. Tokyo: Taimeido. (J)

Ishikawa, Y. ed. 2001a. Studies in the migration turnarounds. Kyoto: Kyoto University Press. (J)

Ishikawa, Y. 2001b. Population geography with GIS in Japan. GeoJournal 52: 189-194.

Ishikawa, Y. ed. 2005. Migration in the Asia/Pacific region. Tokyo: Akashi-shoten. (J)

Ishikawa, Y. ed. 2007. Population decline and regional imbalance: Geographical perspectives. Kyoto: Kyoto University Press. (J)

Ishikawa, Y., and Montanari, A. eds. 2003. The new geography of human mobility: Inequality trends?. Rome: Società Geografica Italiana (IGU Home of Geography Publication Series IV).

Isoda, Y. 2000a. Where do people live and where are they going?: Net migration by age in Great Britain. Journal of Population Studies 26: 35-46.

Isoda, Y. 2000b. Migration to and from Greater London: An irregular escalator?. Geographical Review of Japan 73A: 44-55. (JE)

Ito, S. 2001. Residential choice process of households living in Chiba New Town: The role of husbands and wives in the residential choice process. Geographical Review of Japan 74A: 585-598.(JE)

Jung, M.-A. 2002. Spatial migration patterns and explanatory factors of Bundang New Town residents: Seoul Metropolitan Area. Geographical Review of Japan 75: 791-812.(JE)

Kagami, M. 2004. Geographical view on disease diversity. Tokyo: Kokon-shoin. (J)

Kamiya, H., Kageyama, H., and Kinoshita, R. 2006. Analyzing single women's residential choice in Tokyo by using a qualitative method. Geographical Review of Japan 79: 619-628. (JE)

Kobayashi, K., Mládek, J., Širocková, J., and Kobayashi, T. 2006. Family behavior of Japanese and Slovak populations: Similarities and differences. Geographical Review of Japan 79: 644-663.

Koike, S. 2003. Possibility of applying GIS to historical study on population distribution. Journal of Population Studies 32: 14-18. (JE)

Koike, S. 2006. On the impact of migration on fertility: Can migration reduce fertility?. Journal of Population Problems 62(4): 3-10. (JE)

Koike, S., and Arai, Y. 2001. Making of BGSS system population data from topographical maps pub- 
lished in the Meiji-Era. Theory and Applications of GIS 9: 1-8. (JE)

Koike, S., Nishioka, H., and Yamauchi, M. 2004. On setting assumption values for "population projections by municipality, December 2003": Centering on net migration rates. Journal of Population Problems 60(4): 13-33. (JE)

Kubo, T., and Ishikawa, Y. 2004. Searching for "paradise": Japanese international retirement migration. Japanese Journal of Human Geography 56: 296-309. (JE)

Liaw, K.-L., and Ishikawa, Y. 2008. Destination choice of the 1995-2000 immigrants to Japan: Salient features and multivariate explanation. Environment and Planning $A$ 40: 806-830.

Liu, C., Wang, Q., Ichinose, T., and Otsubo, K. 2005. Spatial distribution and factors influencing the floating population in China. Geographical Review of Japan 78: 586-600. (JE)

Masuyama, A., and Okabe, A. 2003. A method for comparative analysis of urban population distributions and its application to middle-sized cities in Japan. Geographical Review of Japan 76: 759-776. (JE)

Miyazawa, H., and Abe, T. 2005. Recovery and changes in the socioeconomic composition of population in the central area of Tokyo during the period from 1995 to 2000: Analysis of small-area census data. Geographical Review of Japan 78: 893-912. (JE)

Morikawa, H. 2006. Japanese urban systems and their transformations viewed from migration analysis of major cities. Geographical Sciences 61: 243-257. (JE)

Nakagawa, S. 2000. Internal migration in today's Japan. Geographia Polonica 73: 127-140.

Nakagawa, S. 2001. Unbalanced spatial distribution of gender and "migration for marriage" in Japan. Journal of Population Problems 57(1): 25-40. (JE)

Nakagawa, S. 2003. The long-term regional fertility disparity in Japan. Acta Facultatis Naturalium Universitatis Comenianae, Geographica 43: 11-35.

Nakagawa, S. 2004. Changing distribution of gender in the Extended Bangkok Region under globalization. GeoJournal 61: 255-262.

Nakamura, S. 2000. Migration behavior and seasonal migrant workers: The case of Kudoyama Area, Hamasaka Town, Hyogo Prefecture. Japanese Journal of Human Geography 52: 111-128. (JE)

Nakaya, T. 2000. An information statistical approach to the modifiable areal unit problem in incidence rate maps. Environment and Planning A 30: 91-109.
Nakaya, T., and Dorling, D. 2005. Geographical inequalities of mortality by income in two developed island countries. Social Science and Medicine 60: 2865-2875.

Nakaya, T., Fotheringham, S., Brunsdon, C., and Charlton, M. 2005a. Geographically weighted Poisson regression for disease associative mapping. Statistics in Medicine 24: 2695-2717.

Nakaya, T., Nakase, K., and Osaka, K. 2005b. Spatiotemporal modelling of the HIV epidemic in Japan based on the national HIV/AIDS surveillance. Journal of Geographical Systems 7: 313-336.

Nakaya, T., Tanimura, S., Nikame, N., and Horikoshi, Y. 2004. Health GIS. Tokyo: Kokon-shoin. (J)

Nakazawa, T. 2001a. Factors of concentration of industrial engineers in the Tokyo Metropolitan Area: Analyzing the job assignment process of university engineering students. Japanese Journal of Human Geography 53: 590-607.(JE)

Nakazawa, T. 2001b. The R\&D labor market for newly graduated engineering students: The process of concentration in the Tokyo Metropolitan Area. Annals of the Japan Association of Economic Geographers 47: 19-34. (JE)

Nakazawa, T. 2002. Labor market for IT engineers and their work careers: A survey in the Kyushu region. Geographical Review of Japan 75: 837857. (JE)

Nakazawa, T. 2006. Residential locations of working women in the Tokyo Metropolitan Area: A case study of office workers in the central business district. Geographical Review of Japan 79: 595607. (JE)

Nakazawa, T., and Arai, Y. 2003. Internet business firms and working careers of their employee in Kyushu region. Annals of the Japan Association of Economic Geographers 49: 218-229. (JE)

Nakazawa, T., and Arai, Y. 2004a. Migration and skill level of information technology engineers in provincial regions. Geographical Review of Japan 77: 675-692.(JE)

Nakazawa, T., and Arai, Y. 2004b. Establishment of information service firms in Hokkaido and Tohoku: Focusing on the migration history of entrepreneur. Annals of the Japan Association of Economic Geographers 50: 162-174. (JE)

Nakazawa, T., and Kamiya, H. 2005. Regional difference in women's life course and causal mechanisms: Life courses after high school graduation in Kanazawa and Yokohama. Geographical Review of Japan 78: 560-585. (JE)

Nakazawa, T., Kamiya, H., and Kinoshita, R. 2006. Regional and gender differences in life course and related factors: Life courses after high school in 
Kanazawa and Yokohama. Japanese Journal of Human Geography 58: 308-326. (JE)

Nakazawa, T., and Kawaguchi, T. 2001.The residential careers of people from the non-metropolitan area within the Tokyo Metropolitan area: A survey of graduates of high schools in Nagano Prefecture. Geographical Review of Japan 74A: 685-708. (JE)

Ochiai, E., Liaw, K.-L., and Ishikawa, Y. 2007. Feminization of immigration to Japan: Mainly focused on international marriage. In Population decline and regional imbalance: Geographical perspectives, ed. Y. Ishikawa, 291-319. Kyoto: Kyoto University Press. (J)

Otomo, A. 1998. Twenty years of regional demography. Journal of Population Studies 23: 55-66. (J)

Otomo, A. 2002. Methods for analyzing regional population. Tokyo: Japan Statistical Association. (J)

Otomo, A. 2003. Size and structures of national populations in the world. Tokyo: Kokon-shoin. (J)

Otomo, A. 2006. Changes and their factors of national populations in the world. Tokyo: Kokonshoin. (J)

Otsuka, T. 2005. Condominium supply and residential preference in the central urban area of Toyohashi City, a medium-scale city in Japan. Geographical Review of Japan 78: 202-227. (JE)

Portnov, B. A., Kim, D.-C., and Ishikawa, Y. 2001. Investigating the effects of employment-housing change on migration: Evidence from Japan. International Journal of Population Geography 7: 189-212.

Sakakibara, A., Matuoka, K., and Miyazawa, H. 2003. Characteristics of condominium residents in the center of Sendai and their residential preferences for city center. Quarterly Journal of Geography 55: 107-121. (JE)

Sato, H., and Arai, Y. 2003. Residential selection behaviors during the suburbanization of office location: Case studies of Omiya, Makuhari and Yokohama. Geographical Review of Japan 76: 450471. (JE)

Sato, Y. 2004. Migration processes of R\&D workers in Tsukuba science city: A case study of the pharmaceutical industry. Annals of the Japan Association of Economic Geographers 50: 205-226. (JE)

Shimizu, M. 2002. Comparing two migration definitions: An analysis of 'last moves within five years' and 'residence five years earlier'. Journal of Population Studies 30: 55-68. (JE)

Shimizu, M. 2004a. The age pattern of net migration rate in central Tokyo: The case of Chiyoda Ward. Journal of Population Problems 60(4): 34-54.
(JE)

Shimizu, M. 2004b. An analysis of recent migration trends in the Tokyo City core 3 wards. Japanese Journal of Population 2: 1-16.

Shimizu, M. 2006. On the quantum and tempo of cumulative net migration. Journal of Population Problems 62(4): 41-60. (JE)

Soda, R. 2007. People on the move: Rural-urban interactions in Sarawak. Kyoto: Kyoto University Press.

Suzuki, M. 2004. Population dynamics of cities and counties and urbanization in the Tokai area during the Meiji and Taisho periods: Analyzing 'Kokoh-Chosa' population statistics. Japanese Journal of Human Geography 56: 470-490. (JE)

Taguchi, J. 2001. Changes in residential mobility and commuting patterns caused by the new railway in Chiba New Town. Geographical Review of Japan 74A: 305-324. (JE)

Tahara,Y., Nagata, A., and Arai, Y. 2000. Examination of process of elderly return migration and its impact: The case of N community, Okinawa Prefecture. Japanese Journal of Gerontology 22: 436448. (J)

Tahara, Y., Hirai, M., Inada, N., Iwadare, M., Naganuma, S., Nishi, R., and Wada, Y. 2003. Towards a gerontological geography: Contributions and perspectives. Japanese Journal of Human Geography 55: 45-67. (JE)

Takeda, Y., and Kinoshita, R. eds. 2007. Gender atlas of Japan. Tokyo: Akashi-shoten. $(\mathrm{J})$

Takeshita, S. 2006. The role of a real estate agency in migration to Yakushima. Japanese Journal of Human Geography 58: 475-488. (JE)

Tanaka, K. 2000a. Analysis of metropolitan spaces. Tokyo: Kokon-shoin. (J)

Tanaka, K. 2000b. A preliminary analysis of spatial trajectories of residential migration in Pretoria, South Africa, Geographical Review of Japan 73B: $119-138$.

Tanaka, K. 2002. Geometrical aspects of intra-urban migration: Migration career and the concept of 'spatial configuration.' Geographical Review of Japan 75: 709-729.

Tani, K. 2002. Changes in the links between home and work after marriage in the Tokyo Metropolitan suburbs. Geographical Review of Japan 75: 623643. (JE)

Tanigawa, N. 2004. Life history of migrants, life story of a community: A case study of the Osumi-shoto Islands. Japanese Journal of Human Geography 56: 393-409. (JE)

Van de Kaa, D. 2002. The idea of a second demographic transition in industrialized countries. 
Journal of Population Problems 58(1): 22-56. (JE)

Wakabayashi, Y. 2006. Residential choices of single women in Tokyo Metropolitan Area: A multimethod approach. Geographical Review of Japan 79: 608-618.

Wakabayashi, Y., Kamiya, H., Kinoshita, R., Yui, Y., and Yano, K. 2002. Metropolitan space for unmarried women. Tokyo: Taimeido. (J)

Yabe, Y. 2003. Population recovery in inner Tokyo in the late 1990s: A questionnaire survey in Minato Ward. Japanese Journal of Human Geography 55: 277-292. (JE)

Yamagami, T. 2001. Recent changes in population distribution in the three largest metropolitan areas of Japan: An analysis using the expanded Clark model. Japanese Journal of Human Geography 53: 509-531. (JE)

Yamagami, T. 2003a. Spatio-temporal structure of population growth in major metropolitan areas in Japan. Geographical Review of Japan 76: 187210. (JE)

Yamagami, T. 2003b. The relation between population size and population increase in metropolitan areas in Japan. Journal of Population Studies 33: 73-83. (JE)

Yamagami, T. 2006. The relationship between metropolitan size and the population redistribution pattern within metropolitan areas in Japan from the perspective of diversity among suburban municipalities. Japanese Journal of Human Geography 58: 56-72. (JE)

Yamaguchi, S. 2004. Administrative labor migration program from Okinawa to 'Mainland' Japan as a foreign country during the United States Civil Administration of the Ryukyu Islands. Japanese Journal of Human Geography 56: 21-42. (JE)

Yamaguchi, Y., Arai, Y., and Esaki, Y. 2000. Migration trends of young jobseekers in and around peripheral regions in Japan. Annals of the Japan Association of Economic Geographers 46: 43-54. (JE)

Yamaguchi, Y., and Esaki, Y. 2002. Methodical recruit- ing systems for high school jobseekers in Japan: A case of connections between southwest Kyushu and the Chukyo metropolitan area through employing female high school graduates. Quarterly Journal of Geography 54: 92-104. (JE)

Yamamoto, K. 2000. Immigration and issues of immigrants in Sweden. Annual Report of Research Center for Regional Geography 9: 1-32. (JE)

Yamauchi, M. 2006. Indices for regional fertility analysis: Definition, advantages, and limitations of the indirect standardized indices of child-woman ratio, child-marital woman ratio and proportion married. Journal of Population Studies 38: 99-110. (JE)

Yamauchi, M., Nishioka, H., and Koike, S. 2005. Fertility in metropolitan and non-metropolitan areas of Japan from 1980 to 2000. Journal of Population Problems 61(1): 1-17. (JE)

Yano, K., Nakaya, T., Fotheringham, A. S., Openshaw, S., and Ishikawa, Y. 2003. A comparison of migration behaviour in Japan and Britain using spatial interaction models, International Journal of Population Geography 9: 419-431.

Yano, K., Nakaya, T., and Ishikawa, Y. 2000. An analysis of inter-municipal migration flows in Japan using GIS and spatial interaction model. Geographical Review of Japan 73B: 165-177.

Yui, Y. 2006. Purchases of condominiums by single women and their backgrounds in Tokyo: Housing problems for women. Geograghical Review of Japan 79: 629-643. (JE)

Yui, Y. 2007. Regional disparity of household diversification. In Population decline and regional imbalance: Geographical perspectives, ed. Y. Ishikawa, 17-41. Kyoto: Kyoto University Press. (J)

Yui, Y., and Yano, K. 2000. Housing problems for single-parent families and the welfare facilities: A case study of Tokyo. Geographical Sciences 55: 77-98. (JE)

$(J)$ : written in Japanese

(JE): written in Japanese with English abstract 